\title{
Gender and age disparity in the initiation of life-supporting treatments: a population- based cohort study
}

Peng-Sheng Ting ${ }^{1}$, Likwang Chen ${ }^{2}$, Wei-Chih Yang ${ }^{2}$, Tien-Shang Huang ${ }^{3}$, Chau-Chung Wu $\mathbf{u}^{4,5}$ and Yen-Yuan Chen ${ }^{4,6^{*}}$ (D)

\begin{abstract}
Background: The relationships between age and the life-supporting treatments use, and between gender and the life-supporting treatments use are still controversial. Using extracorporeal membrane oxygenation as an example of life-supporting treatments, the objectives of this study were: (1) to examine the relationship between age and the extracorporeal membrane oxygenation use; (2) to examine the relationship between age and the extracorporeal membrane oxygenation use; and (3) to deliberate the ethical and societal implications of age and gender disparities in the initiation of extracorporeal membrane oxygenation.

Methods: This is a population-based, retrospective cohort study. Taiwan's extracorporeal membrane oxygenation cases from 2000 to 2010 were collected. The annual incidence rate of extracorporeal membrane oxygenation use adjusting for both age and gender distribution for each year from 2000 to 2010 was derived using the population of 2000 as the reference population. The trend of extracorporeal membrane oxygenation use was examined using time-series linear regression analysis. We conducted joinpoint regression for estimating the trend change of extracorporeal membrane oxygenation use.

Results: The trends of extracorporeal membrane oxygenation use both for different gender groups, and for different age groups have been significantly increasing over time. Men were more likely to be supported by extracorporeal membrane oxygenation than women. Women's perspectives toward life and death, and women's perception of well-being may be associated with the phenomenon. In addition, the patients at the age of 65 or older were more likely to be supported by extracorporeal membrane oxygenation than those younger than 65. Family autonomy/ family-determination, and the Confucian tradition of filial piety and respecting elders may account for this phenomenon.

Conclusions: This study showed gender and age disparities in the initiation of extracorporeal membrane oxygenation use in Taiwan, which may be accounted for by the cultural and societal values in Taiwan. For a healthcare professional who deals with patients'ffamily members' medical decision-making to initiate life-supporting treatments, he/she should be sensitive not only to the legality, but also the societal and ethical issues involved.
\end{abstract}

Keywords: Extracorporeal membrane oxygenation, Cardiopulmonary resuscitation, Life-supporting treatment, Trend, Disparity

* Correspondence: chen.yenyuan@gmail.com

${ }^{4}$ Graduate Institute of Medical Education and Bioethics, National Taiwan

University College of Medicine, Taipei, Taiwan

${ }^{6}$ Department of Medical Education, National Taiwan University Hospital,

Taipei, Taiwan

Full list of author information is available at the end of the article 


\section{Background}

Extracorporeal membrane oxygenation (ECMO) is a technique that uses a modified heart-lung machine to support the severely ill patients for several days or weeks as a bridge to further treatment or while awaiting recovery during cardiac or respiratory failure. Until now, the indications of initiating ECMO are defined as respiratory failure or cardiac failure refractory to conventional intensive care [1-4].

According to Extracorporeal Life Support Registry Report, a collection of ECMO cases reported to Extracorporeal Life Support Organization by hundreds of medical institutions worldwide which operated ECMO, the annual number of ECMO patients gradually rose since 1990. ECMO is mostly used to support neonates who, compared to adults and pediatric patients, not only have the highest rates of surviving ECMO use, but also surviving to hospital discharge [5].

Given that ECMO use to support patients is rapidly increasing $[5,6]$, examining the issues in relation to ECMO use is attracting more and more attention. Most studies on ECMO have focused on outcomes [7-12], and several of them reported that approximately $48 \%$ to $52 \%$ of patients supported by ECMO were male [7-9, 13]. In this study, it is paramount to examine gender and age disparities in ECMO use. The objectives of this study were as follows: (1) to examine the gender disparities in ECMO use; (2) to examine the age disparities in ECMO use; (3) to estimate the trend of ECMO use as stratified by gender; (4) to estimate the trend of ECMO use as stratified by age; (5) to examine the trend change of ECMO use for each gender and age group; and (6) to deliberate the ethical, cultural, and societal implications of the study results.

\section{Methods}

\section{Data collection}

We obtained secondary data from the Taiwan National Health Insurance Research Dataset (NHIRD) by using SAS 9.3 software (for Windows PC) to build our analytical data file. We extracted and organized registration and hospital-care data for all patients supported by ECMO for any length of time between January 1, 2000 and December 31,2010 . We used person-year to estimate the incidence rate of ECMO use. We estimated the annual number of person-years in Taiwan for each year from 2000 to 2010.

\section{Direct standardization}

Because the gender and age distribution in the population changes each year, the population of Taiwan in the year 2000 is used as the reference population in conducting both direct age standardization and direct gender standardization.

The annual incidence rate (IR) of ECMO use adjusting for both age and gender distribution for each year from 2000 to 2010 was derived using the population of 2000 as the reference population. We defined the gender-specific age-adjusted incidence rate of ECMO use (GIR) as the annual number of ECMO cases per million personyears adjusting for age distribution using direct age standardization. The difference in ECMO use between gender groups was then examined by comparing the trend of the GIR for men with that for women. In addition, we defined the age-specific gender-adjusted incidence rate of ECMO use (AIR) as the annual number of ECMO cases per million person-years adjusting for gender distribution using direct gender standardization. We compared the trends of the AIR for each age group: Neonates, aged 30 days and younger; Pediatrics, from the age of 31 days to 17 years old; Adults, from the age of 18 years old to 64 years old; Elders, aged 65 years and older.

\section{Statistical analyses}

We fitted time-series linear regression models to investigate whether the trend of ECMO use was significantly increasing over time. For estimating the trend change, we performed joinpoint regression using Joinpoint Regression Program 3.5.2 for Windows PC [14]. We supplied the minimum and the maximum number of joinpoints as zero and four respectively, the minimal number of observations from a joinpoint to either end of the data as two, and the minimal number of observations between two joinpoints as one. Results with a $p$ value of less than or equal to .05 were regarded as statistically significant. All statistical analyses in this study were carried out using the software package of STATA MP 11.0 for Windows PC.

\section{Results}

The total number of ECMO cases in Taiwan from 2000 to 2010 was 6099 . The annual total number of ECMO cases approximately quadrupled, from 257 cases in 2000 to 1104 cases in 2010. The annual IR of ECMO use in Taiwan approximately quadrupled, from 11.87 cases per million person-year in 2000 to 44.36 cases per million person-year in 2010. The time-series linear regression analysis was used to estimate the trend of the annual IR, and showed that ECMO use in Taiwan has significantly increased over time $(p<.01)$ with the adjusted R-square of 0.78 (Table 1 ).

\section{Extracorporeal membrane oxygenation use between genders}

A total of 1949 (31.96\%) of all ECMO cases were females (Fig. 1). The number of female ECMO cases gradually increased from 87 cases in 2000 to 343 cases in 2010. By comparison, the number of male ECMO cases gradually increased from 170 cases in 2000 to 761 cases in 2010 . As indicated by the GIR, the male GIR increased from 15.50 cases per million person-year in 2000 to 61.38 
Table 1 Extracorporeal membrane oxygenation uses in Taiwan from 2000 to 2010

\begin{tabular}{llll}
\hline Year & Case & $\begin{array}{l}\text { Non-standardized } \\
\text { incidence rate }^{\mathrm{a}}\end{array}$ & $\begin{array}{l}\text { Standardized } \\
\text { incidence rate }^{\mathrm{b}}\end{array}$ \\
\hline 2000 & 257 & 11.87 & 11.87 \\
2001 & 274 & 12.40 & 12.35 \\
2002 & 311 & 13.97 & 13.95 \\
2003 & 461 & 20.58 & 20.43 \\
2004 & 435 & 19.22 & 18.86 \\
2005 & 393 & 17.13 & 16.89 \\
2006 & 413 & 17.87 & 17.59 \\
2007 & 666 & 28.62 & 28.03 \\
2008 & 857 & 36.55 & 35.43 \\
2009 & 886 & 37.68 & 38.35 \\
2010 & 1104 & 46.74 & 44.36 \\
\hline
\end{tabular}

a"Non-standardized incidence rate" means the annual number of ECMO cases per million person-year in that year

"Standardized incidence rate" means the annual number of ECMO cases per million person-year adjusting for the age and gender distribution in 2000

cases per million person-year in 2010, while the female GIR increased from 8.19 cases per million person-year in 2000 to 26.98 cases per million person-year in 2010 . The male GIR to the female GIR ratio was 1.89 and 2.27 in 2000 and 2010 respectively, with the lowest ratio of 1.66 in 2001 and the highest ratio of 2.54 in 2003 (Table 2).

We identified that the trend of the male GIR was significantly increasing since 2000 ( $\beta$ coefficient $=4.42$, $p<.01$, adjusted R-square $=0.81$ ). The trend of the female GIR was also significantly increasing over time ( $\beta$ coefficient $=1.82, p<.01$, adjusted R-square $=0.85$ ). However, the male GIR to the female GIR ratio demonstrated a yearly increment of 0.04 , which is not statistically significant $(p=.13)$ (Fig. 2).

Joinpoint regression for the trend of the male GIR and the trend of the female GIR finally selected the model with one joinpoint in 2006 as the best-fit models. In comparison, the best-fit model for the male GIR to the female GIR ratio selected by joinpoint regression was the model with no joinpoint (Table 3).

\section{Extracorporeal membrane oxygenation use between age groups}

A total of 115 (1.89\%), 605 (9.92\%), 3424 (56.14\%), and 1955 (32.05\%) of all ECMO cases were Neonates, Pediatrics, Adults, and Elders, respectively (Fig. 1). The number of Neonates, Pediatrics, Adults and Elders ECMO cases gradually increased from $8,25,142$, and 82 cases in 2000 to $11,79,644$, and 370 cases in 2010, respectively. As indicated by the AIR, Neonates AIR increased from 330.98 cases per million person-year in 2000 to 887.44 cases per million person-year in 2010 . Pediatrics AIR increased from 4.47 cases per million person-year in 2000 to 17.13 cases per million personyear in 2010. Adults AIR increased from 10.12 cases per million person-year in 2000 to 39.58 cases per million person-year in 2010. Elders AIR increased from 44.39 cases per million person-year in 2000 to 157.39 cases per million person-year in 2010 (Table 4).

We used time-series linear regression analysis to examine the trends of Neonates AIR, Pediatrics AIR, Adults AIR, and Elders AIR. We found that all of the four trends of AIR were significantly increasing over time, with $p$ values of .02 ( $\beta$ coefficient $=60.44),<.01$ $(\beta$ coefficient $=1.44),<.01 \quad(\beta$ coefficient $=2.86),<.01$ ( $\beta$ coefficient $=9.94)$ for Neonates AIR, Pediatrics AIR, Adults AIR and Elders AIR, respectively. (Fig. 2).

Joinpoint regression for the trend of Adult AIR finally selected the model with one joinpoint in 2006 as the best-fit model. In comparison, the best-fit model for the trend of Neonates AIR, Pediatrics AIR and Elders AIR selected by Joinpoint Regression was the model with no joinpoint (Table 3).

\section{Discussion \\ Main findings}

An examination of gender and age disparities of ECMO use demonstrated that both the numbers of the male

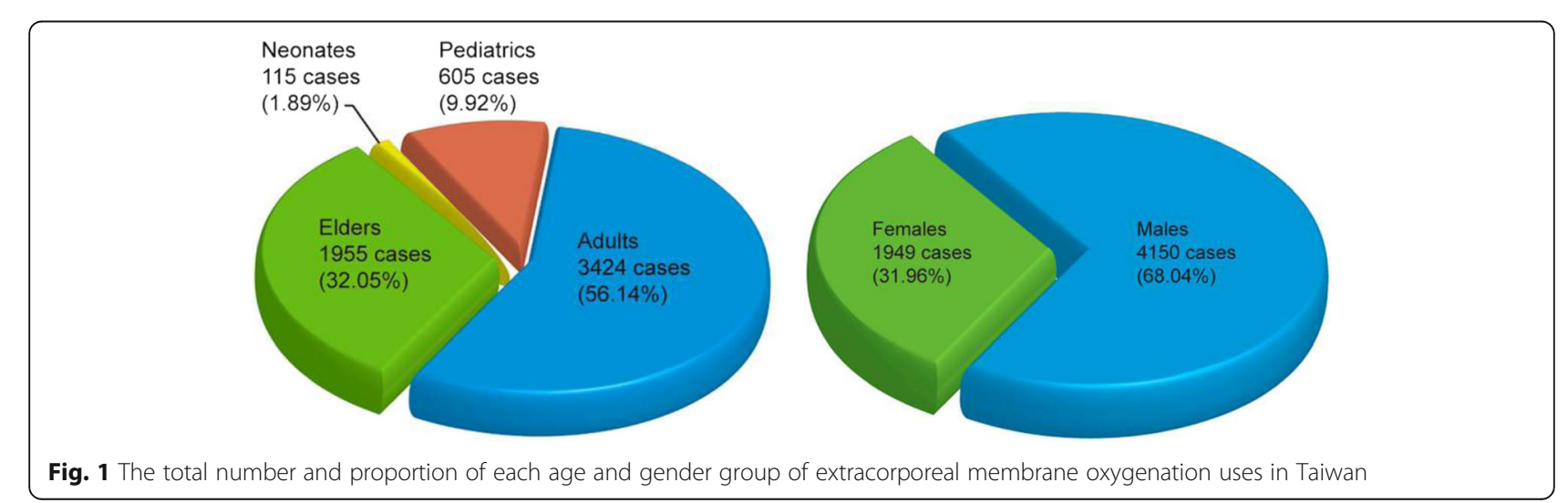


Table 2 The comparison of extracorporeal membrane oxygenation uses between different gender groups

\begin{tabular}{|c|c|c|c|c|}
\hline & \multicolumn{2}{|l|}{ Case } & \multicolumn{2}{|c|}{ Incidence } \\
\hline & Male & Female & Male & Female \\
\hline Year & $\mathrm{N}$ & $\mathrm{N}$ & $G \mathbb{R}^{a}$ & $G \mid R^{a}$ \\
\hline 2000 & 170 & 87 & 15.50 & 8.19 \\
\hline 2001 & 173 & 100 & 15.37 & 9.28 \\
\hline 2002 & 211 & 100 & 18.62 & 9.12 \\
\hline 2003 & 331 & 128 & 29.12 & 11.47 \\
\hline 2004 & 291 & 141 & 25.27 & 12.28 \\
\hline 2005 & 250 & 142 & 21.34 & 12.50 \\
\hline 2006 & 276 & 137 & 23.58 & 11.42 \\
\hline 2007 & 451 & 215 & 37.97 & 17.88 \\
\hline 2008 & 585 & 272 & 48.45 & 21.96 \\
\hline 2009 & 651 & 284 & 53.21 & 23.19 \\
\hline 2010 & 761 & 343 & 61.38 & 26.98 \\
\hline
\end{tabular}

${ }^{\mathrm{a}} \mathrm{GIR}$ denotes for "gender-specific age-adjusted incidence rate of extracorporeal membrane oxygenation," which means the annual number of ECMO cases per million person-year adjusting for age distribution in 2000

The gender status of some ECMO users in the NHIRD is missing: one in 2001, two in 2003, three in 2004, and one in 2004

and female ECMO cases have dramatically increased since 2000. Male patients were more likely to be supported by ECMO than female patients, with the male GIR to the female GIR ratio ranging from 1.69 to 2.57. In addition, Neonates AIR, Pediatrics AIR, Adults AIR and Elders AIR have significantly increased since 2000. Among the four age groups, patients aged 65 years and older (Elders) were much more likely than patients aged from 31 days to 17 years (Pediatrics), and from 18 years to 64 years (Adults) to be supported by ECMO. Particularly, the trends of the male GIR, the female GIR and Adult AIR all had a joinpoint in 2006, implying a significant trend change of ECMO use following 2006.

\section{Gender disparity in extracorporeal membrane oxygenation use}

It is common that male patients receive more lifesupporting treatments (LSTs) than female patients. Goodlin et al. reported that, based on SUPPORT dataset (the Study to Understand Prognoses and Preferences for Outcomes and Risks of Treatments), male patients were more likely to receive cardiopulmonary resuscitation (CPR) than female patients with an odds ratio of 1.39 [15]. Ahn et al. examined the relationship between gender and CPR efforts, and found that only $37 \%$ of resuscitated patients were female [16]. Some studies tried to explain these results by examining women's attitudes toward LSTs use.

A study, using hypothetical scenarios, showed that women expressed a significantly weaker will to live than men, as well as less desire to prolong life by LSTs in all the scenarios presented to them [17]. Bookwala et al. examined gender differences in the preferences for LSTs in response to various health state scenarios, and suggested that men preferred LSTs more than women, while women showed a greater desire for death with dignity and better quality of life than men [18]. These studies, based on both actual cases and hypothetical scenarios, demonstrated that women receive fewer LSTs, or prefer to receive fewer LSTs than men.

Our study results are consistent with the cross-cultural phenomenon that women receive fewer LSTs than men. However, the differences between gender groups in receiving LSTs as indicated by ECMO use is much more profound in Taiwan than those reported by the rest of the world. Several reasons may account for the remarkable difference in gender disparities of ECMO use.

Women's perspectives toward life and death may account for why women receive fewer LSTs. As proposed by Carmel, women usually play a more paramount role than men as a care-giver when their family members are ill, and therefore have much more experience being exposed to aggressive LSTs to extend life and severely compromised quality of life for those being supported by LSTs. Women therefore are more likely to accept the limitations of medical interventions to support life. Encountering more critical illness, women may be less likely than men to insist on LSTs to extend life [17]. Therefore, the different life experiences between men and women may account for the gender disparity in ECMO use in Taiwan.

Women's perception of well-being is also a crucial factor associated with their less willingness to request LSTs. Gender-based difference in well-being has been reported by many social scientists. They stated that, although women live obviously longer than men, they are socially and psychologically disadvantaged on most indicators of well-being [19, 20]. As a result, when encountering critical illness, they are less likely to request LSTs than men.

In addition, women's self-perceived burden to others may explain the gender disparity in LSTs use as indicated by ECMO. According to a study conducted by Tang et al., women were more likely to perceive themselves as a burden to others in face of end-of-life decision-making than men were [21]. Thus, women would be more likely to consent to a DNR order for relieving their self-perceived burden to others.

Age disparity in extracorporeal membrane oxygenation use Several studies have demonstrated that age is associated with the use of LSTs. Goodlin et al. reported that older patients were less likely to be resuscitated [15]. Brandberg et al. found that patients above 80 years old received fewer 

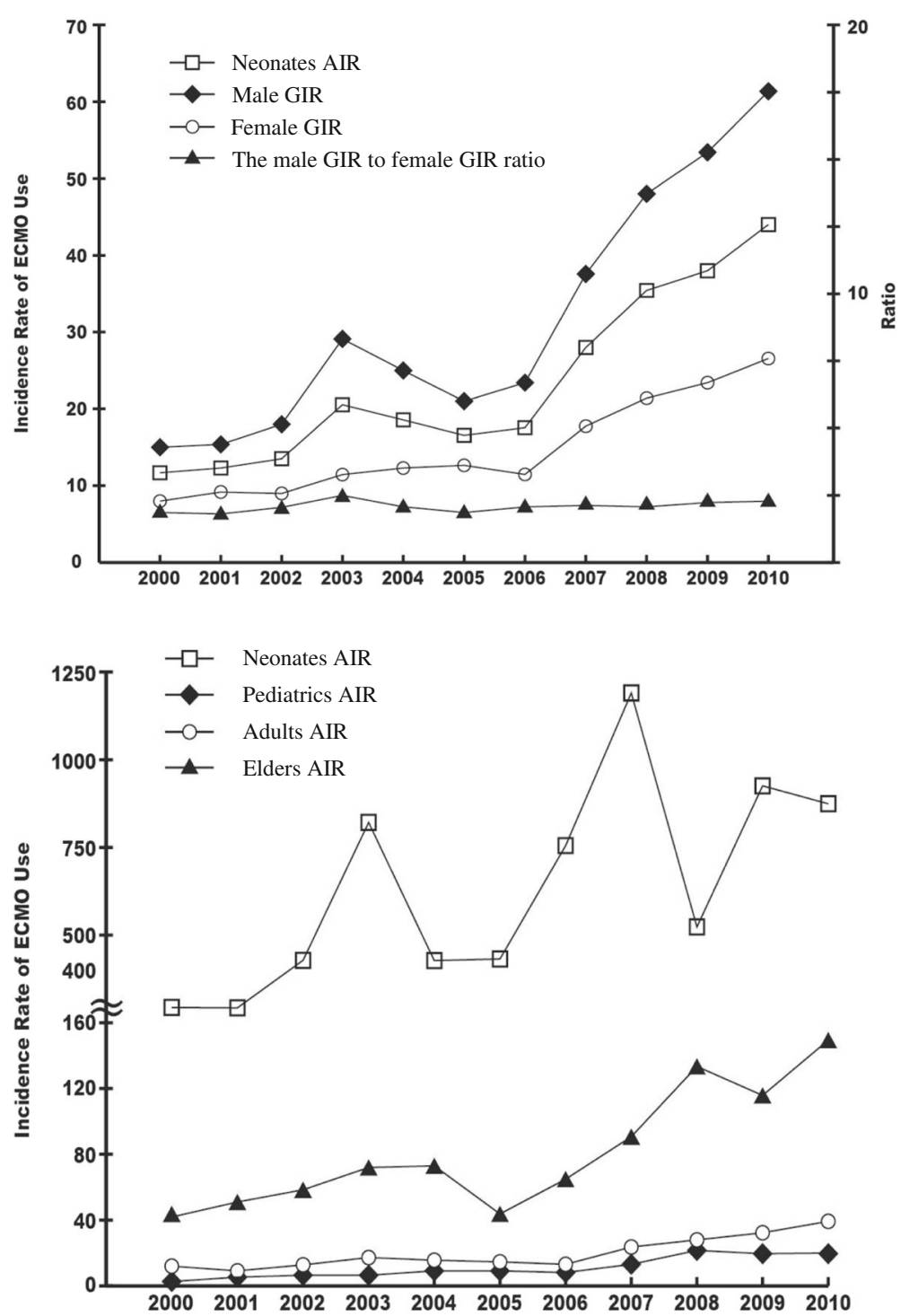

Fig. 2 The trend of each age and gender group of extracorporeal membrane oxygenation uses from 2000 to 2010 in Taiwan

Table 3 Joinpoint Regression Analysis for the trends of extracorporeal membrane oxygenation uses over time

\begin{tabular}{|c|c|c|c|}
\hline & Joinpoint & Pre-joinpoint slope & Post-joinpoint slope \\
\hline $\mathrm{IR}^{\mathrm{a}}$ & One joinpoint at 2006 & 1.34 & 6.27 \\
\hline Female $G \mathbb{R}^{b}$ & One joinpoint at 2006 & 0.84 & 3.54 \\
\hline Male GIR & One joinpoint at 2006 & 1.84 & 8.94 \\
\hline M/F ratio ${ }^{c}$ & No joinpoint & Not applicable & Not applicable \\
\hline Neonate AIR ${ }^{d}$ & No joinpoint & Not applicable & Not applicable \\
\hline Pediatric AIR & No joinpoint & Not applicable & Not applicable \\
\hline Adult AIR & One joinpoint at 2006 & 1.13 & 5.90 \\
\hline Elder AIR & No joinpoint & Not applicable & Not applicable \\
\hline
\end{tabular}

${ }^{a} \mathrm{IR}$ denotes for "the incidence rate of extracorporeal membrane oxygenation use adjusting for gender and age"

bGIR denotes for "gender-specific age-adjusted incidence rate of extracorporeal membrane oxygenation use"

"M/F ratio denotes for "the male GIR to female GIR ratio"

'AIR denotes for "age-specific gender-adjusted incidence rate of extracorporeal membrane oxygenation use" 
invasive interventions compared with patients aged between 65 and 79 [22]. Another study conducted by Reignier et al. showed that patient age is an independent predictor of the medical decision to forgo LSTs [23]. All these studies conducted in Western societies consistently showed that older age was associated with fewer LSTs provided to patients.

Based on a study to examine the elderly persons' wishes, Carmel et al. argued that older age was associated with fewer LSTs. They concluded that the most powerful factor to predict patient's choice regarding the use of LSTs is the patient's personal experience with other people's illnesses. Accompanied with the fears of death and dying, the results of such experiences, whether positive or negative, influence the use of LSTs on the same direction. Because personal experiences with other people's critical illnesses are mostly negative, a person with more personal experiences with other people's illnesses is generally less likely to support his/her own life with LSTs [24]. Despite being a convincing argument, it is not evident for the current practice of ECMO in Taiwan.

According to Extracorporeal Life Support Registry Report International Summary January 2017, 44.78\% of reported worldwide ECMO cases were neonates, and $31.07 \%$ of them were adults and older [5]. In comparison, only 115 (1.88\%) ECMO cases were neonates, and 1955 (32.05\%) ECMO cases were elders in Taiwan from 2000 to 2010 (Fig. 1), which are so different from those have been reported by Extracorporeal Life Support Registry Report International Summary January 2017. Our findings contradict many studies which clearly reported that older patients tend to receive fewer LSTs [25-27]. Several reasons may account for this unique situation:

First, individual autonomy/self-determination and family autonomy/family-determination: Western societies mostly honor individual autonomy/self-determination, while Taiwan, as part of East Asian societies where Confucianism is influential, mostly values family autonomy/ family-determination. Fan and Lee both proposed the theoretical foundations, based on Confucianism, in support of family autonomy/family-determination in the EastAsian societies, and also highlighted the distinctions between individual autonomy/self-determination and family autonomy/family-determination [28, 29]. Although Chen et al. had reported that the Western societal value of individual autonomy/self-determination has been more and more influential, the East Asian societal value of family autonomy/ family-determination undoubtedly still remain more influential [30]. In addition, surrogate decision-making by family members is more prevalent in the initiation of ECMO than the initiation of other LSTs [31], because patients, suffering from cardiac or respiratory failure refractory to conventional treatment, are usually incapable of autonomous decision-making. Therefore, a patient's self-determination, usually influenced by his/her personal experiences with other people's critical illness as proposed by Carmel et al., plays little role in determining whether to receive LSTs or not. Especially when patients are imminently dying, family members as the surrogate decisionmakers tend to overestimate patient preference for the use of LSTs [32], and in Taiwan, family members usually have poor-to-fair consensus on LST-related issues [33].

Table 4 The comparison of extracorporeal membrane oxygenation uses between different age groups

\begin{tabular}{|c|c|c|c|c|c|c|c|c|}
\hline & Case & & & & Incidence & & & \\
\hline & $\begin{array}{l}\text { Younger than } \\
30 \mathrm{~d} / \mathrm{o}^{\mathrm{a}}\end{array}$ & $31 \mathrm{~d} / \mathrm{o}-17 \mathrm{y} / \mathrm{o}^{\mathrm{b}}$ & $18 \mathrm{y} / \mathrm{o}-64 \mathrm{y} / \mathrm{o}$ & $\begin{array}{l}\text { Older than } \\
65 \text { years }\end{array}$ & $\begin{array}{l}\text { Younger than } \\
30 \mathrm{~d} / \mathrm{o}\end{array}$ & $31 \mathrm{~d} / \mathrm{o}-17 \mathrm{y} / \mathrm{o}$ & $18 \mathrm{y} / \mathrm{o}-64 \mathrm{y} / \mathrm{o}$ & $\begin{array}{l}\text { Older than } \\
65 \text { years }\end{array}$ \\
\hline Year & $N$ & $\mathrm{~N}$ & $\mathrm{~N}$ & $\mathrm{~N}$ & $A I R^{C}$ & AIR & AIR & AIR \\
\hline 2000 & 8 & 25 & 142 & 82 & 330.98 & 4.47 & 10.12 & 44.39 \\
\hline 2001 & 6 & 35 & 138 & 94 & 294.36 & 6.33 & 9.51 & 50.34 \\
\hline 2002 & 8 & 35 & 155 & 113 & 428.51 & 6.41 & 10.55 & 58.77 \\
\hline 2003 & 15 & 42 & 261 & 141 & 844.33 & 7.80 & 17.59 & 71.31 \\
\hline 2004 & 7 & 49 & 230 & 146 & 425.53 & 9.33 & 15.25 & 72.11 \\
\hline 2005 & 7 & 50 & 239 & 96 & 430.93 & 9.74 & 15.55 & 46.01 \\
\hline 2006 & 12 & 44 & 215 & 142 & 752.59 & 8.53 & 13.81 & 66.09 \\
\hline 2007 & 19 & 63 & 383 & 201 & 1197.19 & 12.58 & 24.30 & 91.18 \\
\hline 2008 & 8 & 102 & 451 & 296 & 523.99 & 20.77 & 28.20 & 131.55 \\
\hline 2009 & 14 & 81 & 566 & 274 & 930.88 & 17.11 & 35.17 & 119.39 \\
\hline 2010 & 11 & 79 & 644 & 370 & 887.44 & 17.13 & 39.58 & 157.39 \\
\hline
\end{tabular}

${ }^{a} \mathrm{~d} / \mathrm{o}$ denotes for "days old"

by/o denotes for "years old"

"AIR denotes for "age-specific gender-adjusted incidence rate of extracorporeal membrane oxygenation," which means the annual number of ECMO cases per million person-year adjusting for the gender distribution in 2000 
Second, the Confucian tradition of filial piety and respecting elders: Taiwan, as well as other East Asian countries, is deeply influenced by Confucianism. One of the core values highlighted by Confucianism is filial piety and respect for elders. Therefore, when the elder is imminently dying, family members are more likely to request LSTs for the elder as a token of their filial piety and respect for the elder than the family members in Western societies in a similar situation. In addition, to avoid being labeled as having no filial piety and no respect for elders, family members are unlikely to request withholding or withdrawing LSTs, even when they may realize that withholding or withdrawing LSTs for the elder is ethically appropriate.

Trend change in extracorporeal membrane oxygenation use Prior studies have proposed the possibility that the significantly increased ECMO uses in Taiwan's population might be associated with significant social events [6] and their related over-optimistic reports on the Internet and newspapers [34]. We also highlighted the possibility that the media literacy of the audience, i.e. patients, family members, and health care workers, might play an important role on medical decision-making, as well as decision-making to initiate, withhold, or withdraw LSTs [35]. By further stratifying into different sub-populations, we found that the ECMO use was significantly increased following 2006 in both gender groups and in the adult population. Therefore, the decision-making of both gender groups and the adult population to initiate ECMO might be influenced by information from the media. How the media literacy of an individual associates with LSTs decision-making, as well as other medical decision-making, should be further investigated in the future.

By studying gender and age disparities in LSTs as represented by ECMO use, we found that men were more likely than women to be supported by ECMO, which can be partly explained as the result of patriarchy, gender discrimination towards women in Taiwan, women's negative life experiences with critical illness, as well as women's perceptions of well-being in a society. In addition, elderly patients in Taiwan were more likely to be supported by ECMO than in the rest of the world, which could reflect the adherence to the core values of filial piety and respect for the elders. Our study results suggest that patients'/family members' medical decisionmaking to request the use of LSTs is highly associated with the societal and cultural values of the particular context. Therefore, for a healthcare professional who deals with patients'/family members' medical decisionmaking to initiate, withhold or withdraw LSTs, he/she should be sensitive not only to the legality, but also the societal and cultural values involved.

\section{Strengths and limitations}

By obtaining nationwide data, we were able to firstly examine the gender and age disparities of ECMO use in this population-based study. This study accurately estimated the annual ECMO use per million person-years for gender and age groups using direct standardization, and the population of Taiwan in the year 2000 as the reference population in conducting both direct age standardization and direct gender standardization.

Our study also has a number of limitations. First, this study was conducted in Taiwan, which has the highest prevalence rate of ECMO use in the world. The external generalizability of the results might be of concerns. Second, ECMO use was identified relying exclusively on the Taiwan NHIRD, which is reliable, but not completely so. Nevertheless, our sample size is so large that the missing data and few unreliable data are negligible, and does not obscure the implication of the study results. Third, given that this is a population-based, retrospective study, we would never know whether the criteria for initiating ECMO use were strictly followed in all cases included in this study.

\section{Conclusion}

Taiwan has become the country with the most prevalent ECMO use in the world. We examined the current medical practice of ECMO with a particular focus on the differences between gender and age groups, as well as the trend change of ECMO use in different groups. We identified the disparities in ECMO use in different gender and age groups, and also the increasing ECMO use following 2006 in both gender groups and the adult group. The study results suggested that patients'/family members' medical decisionmaking to request LSTs is associated with the ethical, cultural, and societal values surrounding the particular context. Future studies may be focused on further examining the ethical, cultural, and societal implications related to the gender and age disparities of ECMO use in Taiwan using qualitative research methods.

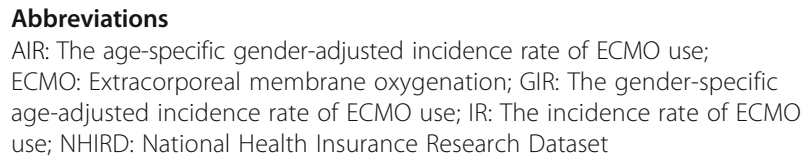

\section{Acknowledgements}

Not applicable.

\section{Funding}

This study was supported by the research grants from Taiwan Ministry of Science and Technology (MOST 103-2511-S-002-008-MY5), National Taiwan University Hospital (NTUH 106-3553) and by Taiwan National Health Research Institutes (PH-100-PP-19 and PH-101-PP-16). The funding agencies did not have any involvement in data collection, data analysis, and data interpretation. 


\section{Availability of data and materials}

The datasets generated and/or analyzed during the current study are available in Taiwan's National Health Insurance Research Dataset, and are available from the corresponding author on reasonable request.

\section{Authors' contributions}

PT, YC and TH reviewed the literature. PT, LC and YC generated the study design. LC and WY retrieved the dataset from NHIRD for this study. LC, WY, CW and YC analyzed and interpreted the patient data. PT, LC and YC draft the text of this article. PT and $Y C$ revised the text of this article. All authors read and approved the final manuscript.

\section{Ethics approval and consent to participate}

This study was approved by the Research Ethics Committee in National Taiwan University Hospital (201212043W). The participants' consents to join this study were waived.

\section{Consent for publication}

Not applicable.

\section{Competing interests}

The authors declare that they have no competing interests.

\section{Publisher's Note}

Springer Nature remains neutral with regard to jurisdictional claims in published maps and institutional affiliations.

\section{Author details}

'Department of Medicine, National Taiwan University College of Medicine, Taipei, Taiwan. ${ }^{2}$ Institute of Population Health Sciences, National Health Research Institutes, Miaoli, Taiwan. ${ }^{3}$ Department of Medical Education, Cathay General Hospital, Miaoli, Taiwan. ${ }^{4}$ Graduate Institute of Medical Education and Bioethics, National Taiwan University College of Medicine, Taipei, Taiwan. ${ }^{5}$ Department of Internal Medicine, National Taiwan University Hospital, Taipei, Taiwan. ${ }^{6}$ Department of Medical Education, National Taiwan University Hospital, Taipei, Taiwan.

\section{Received: 18 March 2017 Accepted: 8 November 2017}

\section{Published online: 15 November 2017}

\section{References}

1. Crow S, Fischer AC, Schears RM. Extracorporeal life support: utilization, cost, controversy, and ethics of trying to save lives. Semin Cardiothorac Vasc Anesth. 2009;13(3):183-91. 10.1177/1089253209347385.

2. Delius RE, Bove EL, Meliones JN, Custer JR, Moler FW, Crowley D, et al. Use of extracorporeal life support in patients with congenital heart disease. Crit Care Med. 1992;20(9):1216-22.

3. Kolla S, Awad SS, Rich PB, Schreiner RJ, Hirschl RB, Bartlett RH. Extracorporeal life support for 100 adult patients with severe respiratory failure. Ann Surg. 1997;226(4):544-66.

4. Moler FW, Custer JR, Bartlett RH, Palmisano JM, Akingbola O, Taylor RP, et al. Extracorporeal life support for severe pediatric respiratory failure: an updated experience 1991-1993. J Pediatr. 1994;124(6):875-80

5. Extracorporeal Life Support Organization. Extracorporeal life support (ECLS) registry report international summary. Ann Arbor, MI: Extracorporeal Life Support Organization; 2017.

6. Chen YY, Chen L, Huang TS, Ko WJ, Chu TS, Ni YH, et al. Significant social events and increasing use of life-sustaining treatment: trend analysis using extracorporeal membrane oxygenation as an example. BMC Med Ethics. 2014;15:21.

7. Rajagopal SK, Almond CS, Laussen PC, Rycus PT, Wypij D, Thiagarajan RR. Extracorporeal membrane oxygenation for the support of infants, children, and young adults with acute myocarditis: a review of the extracorporeal life support organization registry. Crit Care Med. 2010;38(2):382-7.

8. Morris MC, Ittenbach RF, Godinez RI, Portnoy JD, Tabbutt S, Hanna BD, et al. Risk factors for mortality in 137 pediatric cardiac intensive care unit patients managed with extracorporeal membrane oxygenation. Crit Care Med. 2004; 32(4):1061-9.

9. Hemmila MR, Rowe SA, Boules TN, Miskulin J, McGillicuddy JW, Schuerer DJ, et al. Extracorporeal life support for severe acute respiratory distress syndrome in adults. Ann Surg. 2004;240(4):595-605. discussion-7
10. Bartlett RH, Roloff DW, Custer JR, Younger JG, Hirschl RB. Extracorporeal life support: the University of Michigan experience. JAMA. 2000;283(7):904-8.

11. Hsu KH, Chi NH, Yu HY, Wang CH, Huang SC, Wang SS, et al. Extracorporeal membranous oxygenation support for acute fulminant myocarditis: analysis of a single center's experience. Eur J Cardiothorac Surg. 2011;40(3):682-8.

12. Chung SY, Sheu JJ, Lin YJ, Sun CK, Chang LT, Chen YL, et al. Outcome of patients with profound cardiogenic shock after cardiopulmonary resuscitation and prompt extracorporeal membrane oxygenation support. A single-center observational study. Circ J. 2012;76(6):1385-92.

13. Hodgson CL, Hayes K, Everard T, Nichol A, Davies AR, Bailey MJ, et al. Longterm quality of life in patients with acute respiratory distress syndrome requiring extracorporeal membrane oxygenation for refractory hypoxaemia. Crit Care. 2012;16(5):R202.

14. National Cancer Institute. Joinpoint Regression Program. Statistical methodology and applications branch and data modeling branch, surveillance research program, National Cancer Institute. 3.5.2 ed; 2011.

15. Goodlin SJ, Zhong Z, Lynn J, Teno JM, Fago JP, Desbiens N, et al. Factors associated with use of cardiopulmonary resuscitation in seriously ill hospitalized adults. JAMA. 1999;282(24):2333-9.

16. Ahn $\mathrm{KO}$, Shin SD, Hwang SS. Sex disparity in resuscitation efforts and outcomes in out-of-hospital cardiac arrest. Am J Emerg Med. 2012;30(9):1810-6.

17. Carmel $\mathrm{S}$. The will to live: gender differences among elderly persons. Soc Sci Med. 2001;52(6):949-58.

18. Bookwala J, Coppola KM, Fagerlin A, Ditto PH, Danks JH, Smucker WD. Gender differences in older adults' preferences for life-sustaining medical treatments and end-of-life values. Death Stud. 2001;25(2):127-49.

19. Arber S, Ginn J. Connecting gender and ageing : a sociological approach. Philadelphia, United States: Open University Press; 1995.

20. Miles A. Women, health, and medicine. Philadelphia, United States: Open University Press; 1991.

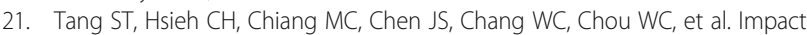
of high self-perceived burden to others with preferences for end-of-life care and its determinants for terminally ill cancer patients: a prospective cohort study. Psychooncology. 2017;26(1):102-8.

22. Brandberg $\mathrm{C}$, Blomqvist $\mathrm{H}$, Jirwe $\mathrm{M}$. What is the importance of age on treatment of the elderly in the intensive care unit? Acta Anaesthesiol Scand. 2013;57(6):698-703.

23. Reignier J, Dumont R, Katsahian S, Martin-Lefevre L, Renard B, Fiancette M, et al. Patient-related factors and circumstances surrounding decisions to forego life-sustaining treatment, including intensive care unit admission refusal. Crit Care Med. 2008;36(7):2076-83.

24. Carmel S, Mutran E. Wishes regarding the use of life-sustaining treatments among elderly persons in Israel: an explanatory model. Soc Sci Med. 1997; 45(11):1715-27.

25. Phillips RS, Wenger NS, Teno J, Oye RK, Youngner S, Califf R, et al. Choices of seriously ill patients about cardiopulmonary resuscitation: correlates and outcomes. SUPPORT investigators. Study to understand prognoses and preferences for outcomes and risks of treatments. Am J Med. 1996;100(2):128-37.

26. Nathens AB, Rivara FP, Wang J, Mackenzie EJ, Jurkovich GJ. Variation in the rates of do not resuscitate orders after major trauma and the impact of intensive care unit environment. J Trauma. 2008;64(1):81-8. discussion 8-91

27. Chen YY, Gordon NH, Connors AF Jr, Garland A, Lai HS, Youngner SJ. Factors associated with two different protocols of do-not-resuscitate orders in a medical ICU*. Crit Care Med. 2014;42(10):2188-96.

28. Fan R. Self-Determination Vs. Family-determination: two incommensurable principles of autonomy: a report from East Asia. Bioethics. 1997;11(3-4):309-22.

29. Lee SC. Intimacy and family consent: a Confucian ideal. J Med Philos. 2015; 40(4):418-36.

30. Chen YY, Tsai SL, Yang CW, Ni YH, Chang SC. The ongoing westernization of east Asian biomedical ethics in Taiwan. Soc Sci Med. 2013:78:125-9.

31. Liu JM, Lin WC, Chen YM, Wu HW, Yao NS, Chen LT, et al. The status of the do-not-resuscitate order in Chinese clinical trial patients in a cancer centre. Med Ethics. 1999;25(4):309-14.

32. Suhl J, Simons P, Reedy T, Garrick T. Myth of substituted judgment. Surrogate decision making regarding life support is unreliable. Arch Intern Med. 1994:154(1):90-6.

33. Liu TW, Wen FH, Wang CH, Hong RL, Chow JM, Chen JS, et al. Terminally ill Taiwanese cancer patients' and family caregivers' agreement on patterns of life-sustaining treatment preferences is poor to fair and declines over a decade: Results from two independent cross-sectional studies. J Pain Symptom Manage. 2017;54(1):35-45.e4. 
34. Chen YY, Chen L, Kao YH, Chu TS, Huang TS, Ko WJ. The over-optimistic portrayal of life-supporting treatments in newspapers and on the internet: a cross-sectional study using extra-corporeal membrane oxygenation as an example. BMC Med Ethics. 2014;15:59.

35. Hsieh RW, Chen L, Chen TF, Liang JC, Lin TB, Chen YY, et al. The association between internet use and ambulatory care-seeking behaviors in Taiwan: a cross-sectional study. J Med Internet Res. 2016;18(12):e319.

Submit your next manuscript to BioMed Central and we will help you at every step:

- We accept pre-submission inquiries

- Our selector tool helps you to find the most relevant journal

- We provide round the clock customer support

- Convenient online submission

- Thorough peer review

- Inclusion in PubMed and all major indexing services

- Maximum visibility for your research

Submit your manuscript at www.biomedcentral.com/submit 